\title{
Development of a multiplex PCR method for identification of four genetically modified maize lines and its application in living modified organism identification
}

\author{
Jin Ho Park - Min-A Seol - Soon-Jae Eum - Il Ryong Kim • Hye Song Lim - Jung Ro Lee $\cdot$ Wonkyun Choi
}

Received: 26 September 2020 / Revised: 12 October 2020 / Accepted: 15 October 2020

(c) Korean Society for Plant Biotechnology

\begin{abstract}
Advances in biotechnology have led to progress in crop genetic engineering to improve agricultural productivity. The use of genetically modified (GM) crops has increased, as have consumers' and regulators' concerns about the safety of GM crops to human health, and ecological biodiversity. As such, the identification of GM crops is a critical issue for developers and distributors, and their labeling is mandatory. Multiplex polymerase chain reaction (PCR) has been developed and its use validated for the detection and identification of GMcrops in quarantine. Herein, we established a simultaneous detection method to identify four GM maize events. Eventspecific primers were designed between the junction region of transgene and genome of four GM maize lines, namely 5307, DAS-40278-9, MON87460, and MON87427. To verify the efficiency and accuracy of the multiplex PCR we used specificity analysis, limit of detection evaluation, and mixed certified reference materials identification. The multiplex PCR method was applied to analyze 29 living, modified maize volunteers collected in South Korea in 2018 and 2019. We performed multiplex PCR analysis to identify events and confirmed the result by simplex PCR using each eventspecific primer. As a result, rather than detecting each event individually, the simultaneous detection PCR method enabled the rapid analysis of 29 GM maize volunteers. Thus, the novel multiplex PCR method is applicable for living modified organism volunteer identification.
\end{abstract}

\footnotetext{
${ }^{\dagger}$ Jin Ho Park and Min-A Seol are co-first authors who have contributed equally to this work.

J. H. Park ${ }^{\dagger} \cdot$ M.-A. Seol ${ }^{\dagger} \cdot$ S.-J. Eum $\cdot$ I. R. Kim $\cdot$ H. S. Lim • J. R. Lee $\cdot$ W. Choi $(\square)$

Division of Ecological Safety, National Institute of Ecology, Seocheon 33657, Republic of Korea

e-mail: wonkyun@nie.re.kr
}

Keywords Living Modified Organism, LMMaize Detection, Multiplex PCR

\section{Introduction}

Since the first commercialized genetically modified (GM) crop in the mid-1990s, these crops have been widely cultivated as sources of fodder and food across the world as a result of advances in modern biotechnology. Recently, twenty six countries cultivated 191.7 million hectares of GM crops in a planting area which added 1.9 million hectares to the record of plantings in 2017 (ISAAA 2018). To overcome the agricultural problems caused by pest emergence and climate change, the developers of GM crops stack traits to offer broad agronomic benefits to farmers (Que et al. 2010).

Maize (Zea mays L.), the crops widely used for an industrial raw material, is a source of food and fodder for animals (Shiferaw et al. 2011). GM maize has approved the most wide spread in the world, with 0.64 billion hectares of GM maize have been grown commercially in 21 years (ISAAA 2018). To detect and identify GM maize, PCRbased methods, especially real-time PCR (qPCR), have been used by enforcement laboratories, and the detection method using qPCR validated by the European Union Reference Laboratory for Genetically Modified Food and Feed (EURL-GMFF) is widely used. Even though qPCR has many benefits for qualification and quantification of GMO analysis, the method also has certain shortcomings, for example, PCR interruption due to the presence of inhibitors and the high costs of establishing the analytical platform (Grelewska-Nowotko et al. 2018).

Broad spectrum of GMO detection may be achieved by targeting universal transgene elements such as p35S and 
tNOS. Despite the wide range of application of these detection methods, significant limitations exist in that these methods can only determine if the sample is GMO or not. To identify the authorized GMO efficiently, the regulators must apply event-specific methods that are target unique junctions between the plant genome and transgenic cassette (Fraiture et al. 2017). Many high-tech PCR methods such as real-time PCR (Cottenet et al. 2013), visual DNA microarray analysis ( $\mathrm{Li}$ et al. 2016), fluorescence capillary gel electrophoresis (Heide et al. 2008a; Heide et al. 2008b; Holck et al. 2010), LAMP PCR (Bhoge et al. 2015; Chen et al. 2011), and digital PCR (Dobnik et al. 2018) have been developed and applied for GM maize identification. These detection methods for GMOs are equipment dependent and this presents challenges for the qualitative detection of GMOs using real-time PCR or digital PCR.

The multiplex PCR detection method was developed for the simultaneous detection of GM crops, but this is a time and cost consuming method because the PCR product needs additional step such as gel electrophoresis analysis to confirm the results (Shrestha et al. 2008). However, there are several under-equipped laboratories in need of reliable, simple, feasible and rapid analytical methods for detecting and identifying GMO in samples for regulatory purposes.

In this study, we have established an event specific multiplex PCR method for four GM maize that have been approved in South Korea recently and had not been developed for multiplex PCR. To confirm the specificity and efficiency of the developed multiplex PCR method, we evaluated the limit of detection (LOD), identified mixed certified reference materials (CRMs), and analyzed GMO monitoring samples. Based on the results, we propose that this newly developed multiplex PCR method is applicable for the GM maize identification.

\section{Materials and Methods}

Plant materials and DNA extraction

The CRMs, which are listed in Table 1, were obtained from the Institute for Reference Material and Measurement (IRMM; Geel, Belgium) and American Oil Chemists' Society (AOCS; Urbana, IL, USA). Twenty-nine samples of LM

Table 1 Certified reference material (CRM) used in the present study

\begin{tabular}{|c|c|c|c|c|c|}
\hline Event name & Cat. No. & $\begin{array}{c}\text { CRM } \\
\text { developer }\end{array}$ & $\begin{array}{l}\text { Confidence } \\
\text { level }(\%)\end{array}$ & $\begin{array}{c}\text { Certified } \\
\text { value }(\mathrm{g} / \mathrm{Kg})\end{array}$ & $\begin{array}{c}\text { Uncertainty } \\
(\mathrm{g} / \mathrm{Kg})\end{array}$ \\
\hline 5307 & 0411-D2 & AOCS & 95 & $>977$ & $-84 \sim+23$ \\
\hline DAS-40278-9 & ERM-BF-433d & IRMM & 10 & 100 & 8 \\
\hline MON87460 & 0709-A2 & AOCS & 95 & $>996$ & $-67 \sim+4$ \\
\hline MON87427 & 0512-A & AOCS & 95 & $>994.8$ & $-13 \sim+5.2$ \\
\hline Non-Modified Maize & 0411-C2 & AOCS & N/A & $<1$ & 0.5 \\
\hline DAS-40278-9 Blank & ERM-BF-433a & IRMM & 95 & $\mathrm{~N} / \mathrm{A}$ & N/A \\
\hline MON87427 Blank & 0406-A & AOCS & N/A & N/A & N/A \\
\hline Non-Modified Maize & 0407-A & AOCS & N/A & $<1$ & N/A \\
\hline Bt-11 & ERM-BF-412f & IRMM & 5 & 48.9 & 2.1 \\
\hline NK603 & ERM-BF-415f & IRMM & 5 & 49.1 & 1.3 \\
\hline GA21 & 0407-B & AOCS & 95 & $>991.5$ & N/A \\
\hline MON863 & ERM-BF-416d & IRMM & 10 & 98.5 & $-2.2 \sim+2.5$ \\
\hline 59122 & ERM-BF-424d & IRMM & 10 & 98.7 & 5.8 \\
\hline MIR604 & 0607-A2 & AOCS & N/A & N/A & N/A \\
\hline MON88017 & 0406-D & AOCS & 95 & $>990.7$ & $-68 \sim+9.3$ \\
\hline 98140 & ERM-BF-427d & IRMM & 10 & 96.4 & 9.9 \\
\hline MON89034 & 0906-E & AOCS & 95 & $>996$ & $-53 \sim+4$ \\
\hline Bt-176 & ERM-BF-411f & IRMM & 5 & 50 & 1.8 \\
\hline MIR162 & 1208-A & AOCS & 95 & $>993$ & $-126 \sim+7$ \\
\hline 1507 & ERM-BF-418d & IRMM & 10 & 98.6 & $-1.7 \sim+2.0$ \\
\hline 3272 & ERM-BF-420c & IRMM & 10 & 98 & 8 \\
\hline VCO01981 & ERM-BF-438b & IRMM & 95 & $>986$ & N/A \\
\hline
\end{tabular}

N/A: Not available 
Table 2 Primers used for maize multiplex PCR

\begin{tabular}{|c|c|c|c|c|}
\hline target & Primer Name & Sequence $\left(5^{\prime}-3^{\prime}\right)$ & GC (\%) & Product Size $(b p)$ \\
\hline \multirow{2}{*}{ Adh1 } & Adh1-F & CGTGGTTTGCTTGCCCACA & 58 & \multirow{2}{*}{179} \\
\hline & Adh1-R & CCACTCCGAGACCCTCAGTC & 65 & \\
\hline \multirow{2}{*}{5307} & 5307L-JV1 & ATTATCGCGCGCGGTGTCAT & 55 & \multirow{2}{*}{183} \\
\hline & 5307L-P1 & TGCACCCTTTGCCAGTGG & 61 & \\
\hline \multirow{2}{*}{ DAS-40278-9 } & DAS-40278-9L-P2 & CAGGAGACCTCGCTTGTAACC & 57 & \multirow{2}{*}{215} \\
\hline & DAS-40278-9L-JV1 & TGGTTCATTGTATTCTGGCTTTG & 39 & \\
\hline \multirow{2}{*}{ MON87460 } & MON87460R-F4 & GATGATCTACCATCCACGGATC & 50 & \multirow{2}{*}{319} \\
\hline & MON87460R-JV1 & TCGCGATCCTCCTCAAAGAC & 55 & \\
\hline \multirow{2}{*}{ MON87427 } & MON87427R-F6 & GTGTACATTTAGCTACATCCGATG & 42 & \multirow{2}{*}{363} \\
\hline & MON87427R-JP1 & CCATGTAGATTTCCCGGTTTTCTC & 46 & \\
\hline
\end{tabular}

maize volunteers were collected from 2018 to 2019 in South Korea, and dried using silica gel after sampling. The genomic DNA was extracted from plant samples using DNeasy Plant Mini Kit (Qiagen, Hilden, Germany) following the manufacturer's protocol. Extracted genomic DNA concentrations were quantified by a spectrophotometer ND-2000 (Thermo Fisher Scientific, Waltham, MA, USA). The final DNA concentration was adjusted to $50 \mathrm{ng} / \mu \mathrm{l}$ for PCR analysis and were stored at $-20^{\circ} \mathrm{C}$ until use.

Primer design

As a positive control for all PCR, we used a maize endogenous gene, alcohol dehydrogenase1 (Adhl, GenBank accession No. AF123535). To design the four LM maize event-specific primers, the genetic information of LM events were obtained from the Joint Research Centre-European Commission (JRC-EC) and Center for Environmental Risk Assessment (CERA). The primers which listed in Table 2 were synthesized by Macrogen Inc. (Seoul, Korea) and were diluted to $100 \mathrm{pmol} / \mu \mathrm{l}$ with sterilized water for use.

PCR condition and amplified products detection

The PCR conditions were: 1 cycle of $5 \mathrm{~min}$ at $94^{\circ} \mathrm{C}$ for pre-denaturation, 33 cycles at $94^{\circ} \mathrm{C}$ for denaturation, $30 \mathrm{~s}$ at $59^{\circ} \mathrm{C}$ for primer annealing, $1 \mathrm{~min}$ at $72^{\circ} \mathrm{C}$ for elongation, and $7 \mathrm{~min}$ at $72^{\circ} \mathrm{C}$ for final-extension. The $2 \times$ EF-Taq PCR Pre-Mix (Solgent, Seoul, Korea) and $50 \mathrm{ng} / \mu \mathrm{l}$ genomic DNA and $0.16 \mu \mathrm{M}$ of each primer was used in $30 \mu \mathrm{l}$ final PCR reaction volume. Gel electrophoresis was performed in $2.5 \%$ agarose gel run on $135 \mathrm{~V}$ for $25 \mathrm{~min}$, and gel image was captured using ChemiDoc ${ }^{\mathrm{TM}} \mathrm{XRS}^{+}$(Bio-Rad, Hercules, CA, USA).
Specificity, sensitivity, and LM volunteer analysis

To determine the specificity of the multiplex PCR method, we used genomic DNA from four non-LM maize CRMs and 18 GM maize CRMs including 5307, DAS-40278-9, MON87460, and MON87427. To examine the efficiency of the maize multiplex PCR, we analyzed the LOD and random mixed CRM DNA. For the LOD assay, we serially double-diluted four mixed maize CRM genomic DNA with distilled water to concentrations of 50, 25, 12.5, 6.6, 3.1, 1.6, 0.8 , and $0 \mathrm{ng} / \mu \mathrm{l}$. Random mixtures of CRMs were diluted with non-LM maize genomic DNA to adjust the total DNA which used in reaction. To apply the maize multiplex PCR method for GMO monitoring samples analysis, we performed multiplex PCR using 29 GM maize volunteers collected during 2018 to 2019 in South Korea.

\section{Results and Discussion}

Despite the worldwide cultivation of GM crops and several scientific reports on the risk assessment of GMO, the concerns about the safety of GMO to human health and the environment has led 38 countries worldwide, including South Korea, to prohibit GMO cultivation even though GM crops were approved for use as food and feed and for processing (ISAAA 2018). According to these concerns, the identification of GMO is a critical issue at the regulatory level and for the consumer as well. The GM crop detection strategy is divided into two methods: detection of the inserted gene (DNA-based) and detection of the expressed protein (protein-based). Since the raw materials and processed products of GMO contain introduced gene fragments, they can be identified by detecting the inserted 
(A)

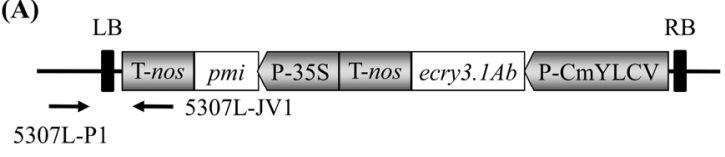

(B)

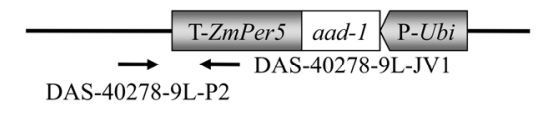

(C)

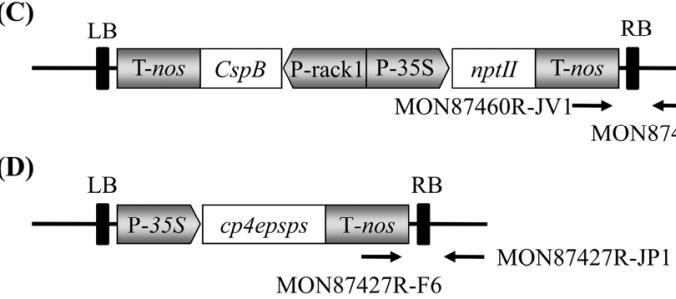

Fig. 1 Schematic diagrams of transgene structure and eventspecific primers for 4 GM maize lines. Primer locations are indicated by arrows. The structural trait genes are shown in open squares, and filled pentagons and squares indicate promoters and terminators respectively. The solid lines indicated the sequence of DNA flanking regions in maize

DNA. These DNA-based methods are usually sensitive, specific, versatile, and widely applicable, but these methods also require long analysis time and special equipment (Michelini et al. 2008). The protein-based methods are less sensitive than the DNA-based methods and might not be suitable for samples containing denatured proteins, such as processed products. Recently, numerous high-throughput DNA-based detection methods have been developed and applied. Among them, the multiplex PCR method, which amplifies multiple DNA targets in one reaction, is a simple strategy for monitoring and screening multiple GM plant samples (Jo et al. 2016; Shin et al. 2016; Eum et al. 2019). Here, we developed a conventional multiplex PCR method for detecting four traits of LM maize, to simply apply to analyze GM maize identification using low cost. Moreover, to identify the GM transgene, we designed a specific primer for each event to target the transformed cassette and plant flanking sequence (Fig. 2, Table 2). These event-specific multiplex PCR methods can detect and identify GMOs in one reaction.

The multiplex PCR detection method has been developed for simultaneous detection of GM maize, but these conventional PCR methods must be followed by an additional step, such as gel electrophoresis, to confirm the result. To overcome this limitation of conventional multiplex PCR, multiplex PCR combined with microarray hybridization or capillary gel electrophoresis was developed (Basak et al. 2014; Schmidt et al. 2008). However, biosensors and microarrays are difficult to commercialize due to instability and

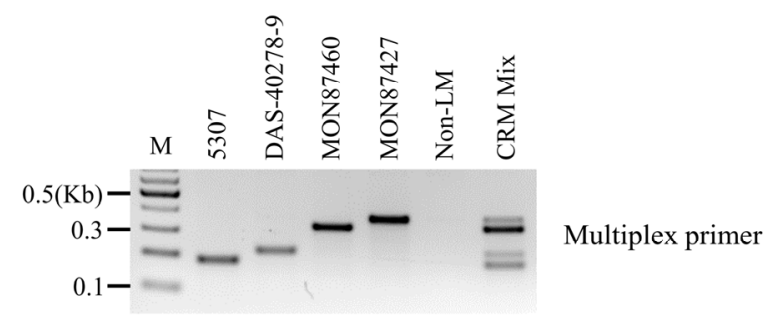

Fig. 2 Establishment of event-specific multiplex PCR for 4 GM maize lines. Agarose gel image of the multiplex PCR with each genomic DNA and multiplex primer. Lane identities are as follows. M: 100 bp marker; lane 1: 5307; lane 2: DAS- 40278-9; lane 3: MON87427; lane 4: MON87460; lane 5: Non-LM; lane 6: 4 CRM mixture

data processing issues (Michelini et al., 2008). To increase the amplification yield and application of multiplex PCR, a multiplex tandem PCR for $35 \mathrm{~S}$ promoter or T-NOS terminator was developed and used for screening GM maize (Wei et al. 2018); however, this method was not applicable for the identification of the stacked GM event due to the repetition of gene cassettes. In this study, a multiplex PCR method to identify four events of GM maize using event-specific PCR primers was developed, and simultaneous detection was found to increase the efficiency of the PCR. These newly developed multiplex PCR method are suitable for qualitative analysis of GM maize (Fig. 2).

Development of multiplex PCR is more complicated than that of simplex PCR, and designing a multiplex assay requires adjustment of many PCR conditions including the concentration of each primer and reaction component (e.g., $\mathrm{MgCl}_{2}$ ) and annealing temperature to amplify all DNA targets simultaneously in a single reaction tube. We used a master mix for the PCR reaction, using one PCR primer concentration $(0.16 \mu \mathrm{M})$ and performed the experiment under general PCR conditions in three steps to simplify the multiplex PCR condition. The data analysis method is also simple that PCR products were separated on $2.5 \%$ single agarose gel (Fig. 2). These results indicate that newly developed multiplex method are feasibly applicable to detect GMO in samples in under-equipped laboratories for regulatory purposes.

To determine the specificity of the developed multiplex PCR, four non-LM CRMs and 18 GM CRMs including four maize CRMs (5307, DAS-40278-9, MON87460, and MON87427) were tested. To assess the reliability, a negative no-template control (NTC) and four maize CRMs as positive controls were tested. All the four positive control CRMs were successfully amplified, while no amplification was observed with NTC and the other 18 maize GM CRMs 


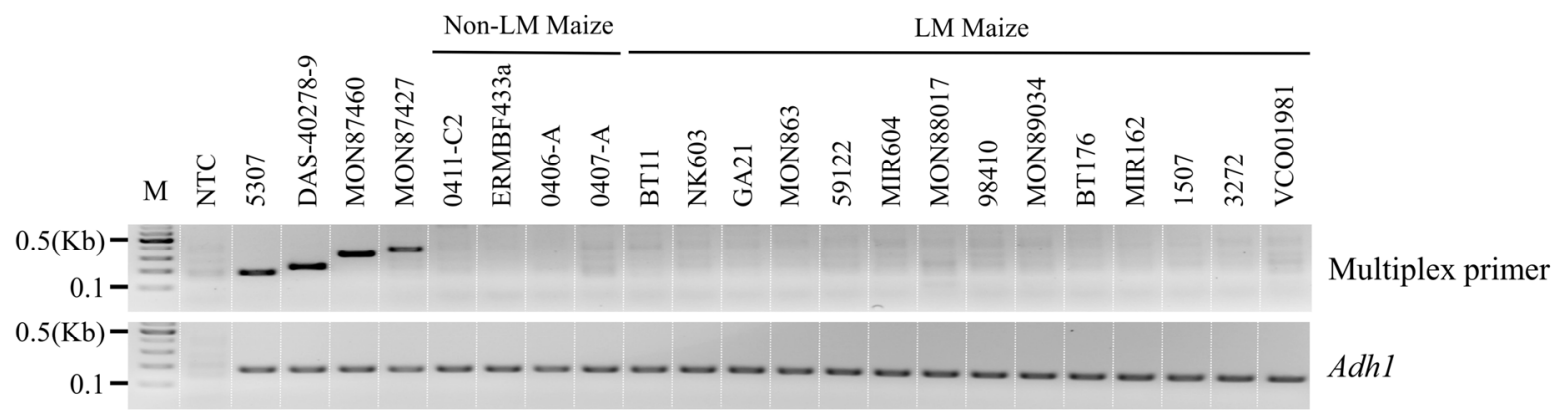

Fig. 3 Specificity of the developed multiplex PCR method. PCR templates are shown above the gel image (4 positive controls: 5307 , DAS-40278-9, MON87460, MON87427; non-LM CRMs: 0411-C2, ERM-BF-433a, 0406-A, 0407-A; 14 maize events: BT11, NK603, GA21, MON863, 59122, MIR604, MON88017, 98410, MON89034, BT176, MIR162, 1507, 3272, VCO01981. Adh1 gene was used for PCR control. M represents a $100 \mathrm{bp}$ marker

including four non-LM CRMs. These results confirm the specificity of the four sets of multiplex PCR primers, indicating that the multiplex PCR method can be applied for volunteer maize sample analysis.

Many powder CRMs from IRMM and AOCS are produced by mixing GM traits and non-GM traits at different GM mass fractions from non-GM to $100 \% \mathrm{GM}$. The blending ratio of CRM is critical during the enforcement of GMO labeling to validate the analytical methods for GMO (Wu et al. 2019). We used $10-100 \%$ pure ( $95 \%$ confidence level) GM maize CRMs (Table 1), and the efficiency of PCR amplification differed for each CRM template. Compared to DAS-40278-9 genomic DNA template $(10 \%$ purity), 5307, MON87460, and MON87427 showed strong amplification (Fig. 2) due to the purity (100\% purify) of CRMs. These different DNA concentrations might be affected in unequal amplification of multiplex PCR. Most volunteer GM maize samples are homozygotes or heterozygotes at least, indicating that the DNA copy number of each volunteer sample is high. Our multiplex PCR also resulted in some weak and dim bands (Fig. 3); however, due to differences of amplification and amplicon size, these were non-specific bands. These results indicate that amplification efficiency and non-specific amplification did

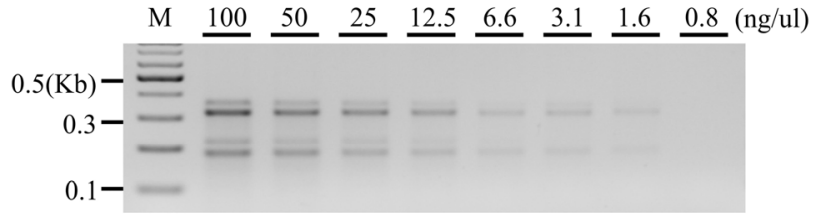

Fig. 4 Limit of detection of multiplex PCR. Four Mixed CRM DNAs were diluted to the following concentrations which are marked in the upper line of the gel image $(100,50,25,12.5$, $6.6,3.1,1.6$, and $0.8 \mathrm{ng} / \mathrm{ul}$ DNA respectively). M represents a 100 bp marker

not affect our PCR results.

The validation of GMO detection methods is very complex and depends on the availability, type, and quality of the template DNA. The quantity and quality of genomic DNA from GMO monitoring samples were not sufficient for analysis; we therefore used LOD and random CRM mixture analysis to verify the efficiency of the multiplex PCR method (Eum et al. 2019). The analysis of serially diluted CRM template DNA revealed that the PCR bands were detected at a DNA concentration of $25 \mathrm{ng} / \mu \mathrm{l}$ (Fig. 4). Moreover, random CRM mixture analysis indicated that the multiplex PCR method can detect stack events without any non-specific band amplification (Fig. 5). These data

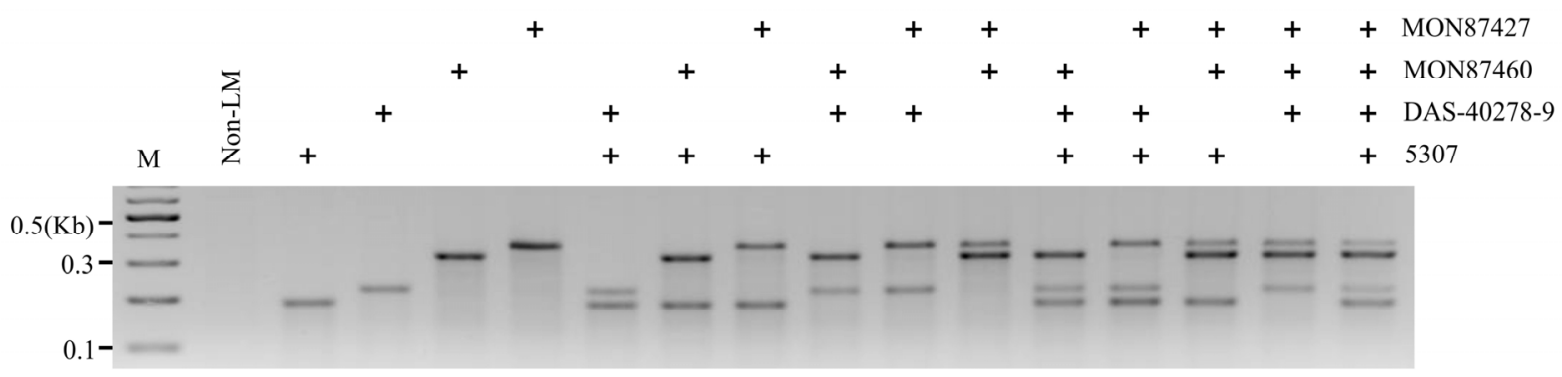

Fig. 5 Efficiency test of multiplex PCR using a random CRM DNA mixture. Total DNA concentration was $50 \mathrm{ng} / \mathrm{ul}$ in each multiplex PCR. Lane identities are as follows: Lane 1, non-LM; Lanes 2-16, random mixtures of LM maize CRMs. M represents a 100 bp marker 
(A)

(H)
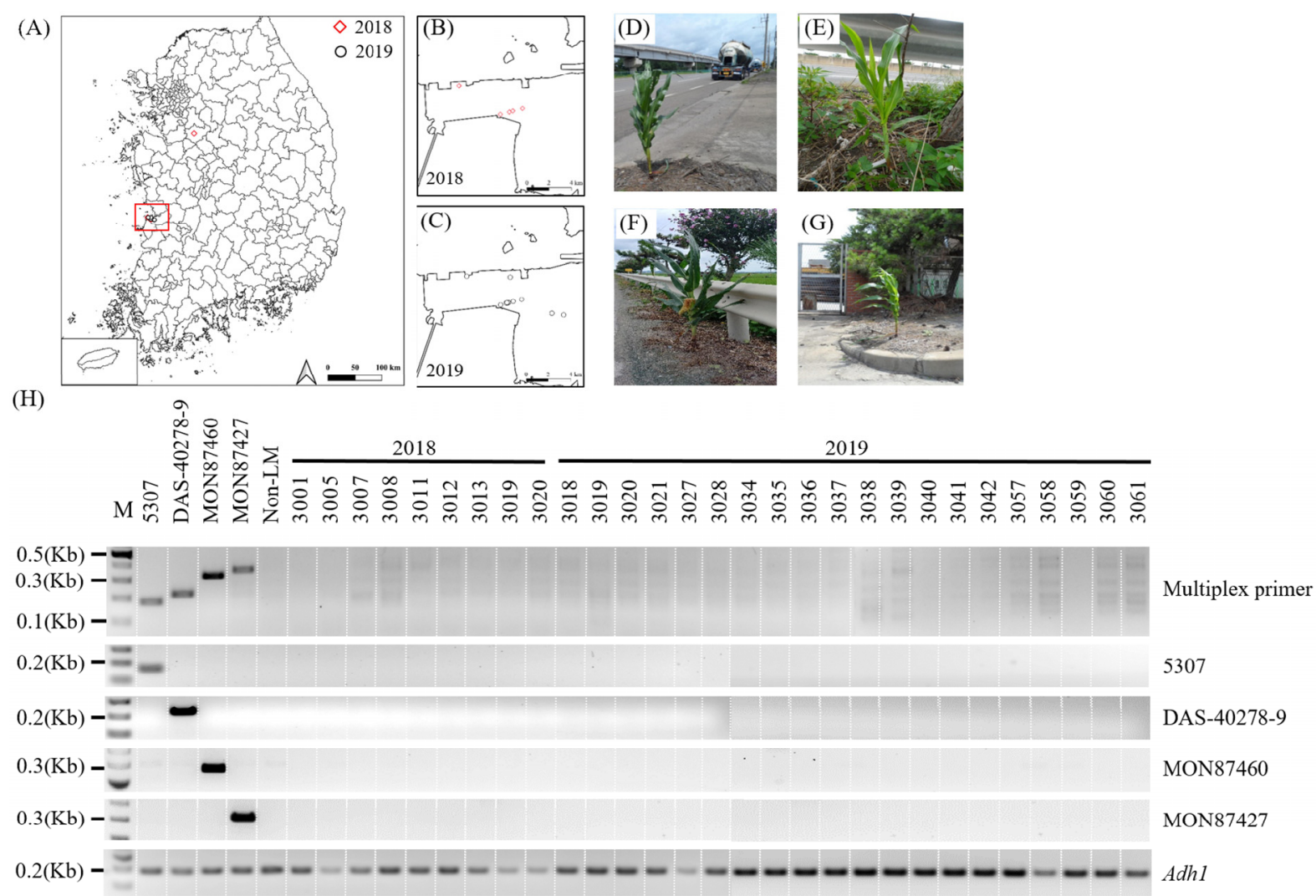

Fig. 6 Application of multiplex PCR for GM maize monitoring sample analysis from 2018 and 2019 in South Korea. (A-C) Map of GM maize monitoring samples in South Korea in 2018 (B), 2019 (C). (D-G) Photographs of the unintentional roadside release of GM maize $(\mathrm{H})$ Identification of multiplex and event-specific PCR for 29 GMO monitoring volunteers. Four CRMs (5307, DAS-40278-9, MON87427, MON87460) were used for the positive control, and non-LM used for a negative control. The sample name from the GMO monitoring was marked at the top of the agarose gel image (2018-3001 to 2019-3061). The primers used for each amplification were marked at the right side of agarose gel image. Adh1 gene was used for PCR control. M represents a 100 bp marker

indicated that maize multiplex PCR was effective for the analysis and identification of four GM maize.

To apply the developed maize multiplex PCR method, we analyzed GMO monitoring samples from 2018 to 2019 in South Korea (Fig. 6A-6C). Most GM maize volunteers were collected from roadsides along major transportation routes for food and feed factories (Fig. 6D-6G). To identify GM maize, we analyzed 29 samples using multiplex PCR and used simplex PCR with the same samples for confirmation. As a result, there is no positive detection with multiplex and simplex PCR in 29 GM maize volunteers (Fig. 6H). These data indicate that 29 GM maize volunteers do not contain four GM maize in their stack traits. However, despite these results, the LOD and random CRM mixture analysis suggest that the multiplex PCR method for 5307, DAS-40278-9, MON87460, and MON87427 might be used for GM maize identification.

\section{Conclusion}

GM maize have been approved and imported for feed and food. To detect and identify newly authorized GM maize event, we need to develop suitable detection method. The results in this study showed that newly developed maize multiplex PCR method have identified successfully for four GM maize (5307, DAS-40278-9, MON87427 and MON87460). To validate the multiplex PCR method, we performed specificity assay, LOD assessment, and random CRM mixture analysis. To apply the multiplex PCR method for GM maize volunteer from 2018 to 2019 in South Korea, we analyzed 29 GM maize sample using multiplex PCR. All these results indicated that newly developed multiplex PCR method are expected to apply for GM maize analysis. 


\section{Acknowledgments}

This work was supported by a grant from the National Institute of Ecology (NIE), funded by the Ministry of Environment (MOE) of the Republic of Korea (NIE-A-2020-06, NIE-A-2020-11).

\section{References}

Basak S, Ehtesham NZ, Sesikeran B, Ghosh S (2014) Detection and identification of transgenic elements by fluorescentPCR-based capillary gel electrophoresis in genetically modified cotton and soybean. J. AOAC Int. 97(1):159-65

Bhoge RK, Chhabra R, Randhawa G, Sathiyabama M, Singh M (2015) Event-specific analytical methods for six genetically modified maize events using visual and real-time loopmediated isothermal amplification. Food Control. 55:18-30

Chen L, Guo J, Wang Q, Kai G, Yang L (2011) Development of the visual loop-mediated isothermal amplification assays for seven genetically modified maize events and their application in practical samples analysis. J. Agric. Food Chem. 59(11): 5914-8

Cottenet G, Blancpain C, Sonnard V, Chuah PF (2013) Development and validation of a multiplex real-time PCR method to simultaneously detect 47 targets for the identification of genetically modified organisms. Anal. Bioanal. Chem. 405(21): 6831-44

Dobnik D, Spilsberg B, Bogožalec Košir A, Štebih D, Morisset D, Holst-Jensen A, Žel J (2018) Multiplex droplet digital PCR protocols for quantification of GM maize events. In: Methods Mol. Biol. Karlin-Neumann G, Bizouarn F, (eds). New York, NY: Humana Press; 1768: 69-98

Eum SJ, Kim IR, Lim HS, Lee JR, Choi W (2019) Event-specific multiplex PCR method for four genetically modified cotton and its application. Appl. Biol. Chem. 62(1):52

Fraiture MA, Herman P, De Loose M, Debode F, Roosens NH (2017) How can we better detect unauthorized GMOs in Food and Feed chains? Trends Biotechnol. 35(6):508-17

Grelewska-Nowotko K, Żurawska-Zajfert M, Żmijewska E, Sowa S (2018) Optimization and verification of droplet digital PCR even-specific methods for the quantification of GM maize DAS1507 and NK603. Appl. Biochem. Biotechnol. 185(1): 207-20

Heide BR, Drømtorp SM, Rudi K, Heir E, Holck AL (2008a) Determination of eight genetically modified maize events by quantitative, multiplex PCR and fluorescence capillary gel electrophoresis. Eur. Food Res. Technol. 227(4):1125-37
Heide BR, Heir E, Holck A (2008b) Detection of eight GMO maize events by qualitative, multiplex PCR and fluorescence capillary gel electrophoresis. Eur. Food Res. Technol. 227(2):527-35

Holck A, Pedersen BO, Heir E (2010) Detection of five novel GMO maize events by qualitative, multiplex PCR and fluorescence capillary gel electrophoresis. Eur. Food Res. Technol. 231:475-483

ISAAA (2018) Global Status of Commercialized Biotech/GM Crops in 2018. Biotech Crops Continue to Help Meet the Challenges of Increased Population and Climate Change. ISAAA Brief No. 54. 2018, Available from: http://www. isaaa.org/resources/publications/briefs/54/default.asp

Jo BH, Seol MA, Shin SY, Kim IR, Choi W, Eum SJ, Song HR, Lee JR (2016) Multiplex PCR method for environmental monitoring of approved LM cotton events in Korea. J. Plant Biotechnol. 43(1):91-8

Li Y, Xiong T, Wu H, Yang Y (2016) Visual DNA microarray coupled with multiplex-PCR for the rapid detection of twelve genetically modified maize. Bio Chip J. 10(1):42-7

Michelini E, Simoni P, Cevenini L, Mezzanotte L, Roda A (2008) New trends in bioanalytical tools for the detection of genetically modified organisms: An update. Anal. Bioanal. Chem. 392(3):355-67

Que Q, Chilton MDM, de Fontes CM, He C, Nuccio M, Zhu T, Wu Y, Chen JS, Shi L (2010) Trait stacking in transgenic crops: Challenges and opportunities. GM Crops 1(4):220-9

Schmidt AM, Sahota R, Pope DS, Lawrence TS, Belton MP, Rott ME (2008) Detection of genetically modified canola using multiplex PCR coupled with oligonucleotide microarray hybridization. J. Agric. Food Chem. 56(16):6791-800

Shiferaw B, Prasanna BM, Hellin J, Banziger M (2011) Crops that feed the world 6. Past successes and future challenges to the role played by maize in global food security. Food Sec. 3:307-327

Shin SY, Lim HS, Seol MA, Jung YJ, Kim IR, Song HR, Lee JR, Choi W (2016) Four multiplex PCR sets of 11 LM maize for LMO environmental monitoring in Korea. J. Plant Biotechnol. 43(4):473-8

Shrestha HK, Hwu KK, Wang SJ, Liu LF, Chang MC (2008) Simultaneous detection of eight genetically modified maize lines using a combination of event- and construct-specific multiplex-PCR technique. J. Agric. Food Chem. 56(19):8962-8

Wei S, Wang C, Zhu P, Zhou G, Fu W, Wu X (2018) A highthroughput multiplex tandem PCR assay for the screening of genetically modified maize. LWT. 87:169-76

Wu Y, Li J, Li X, Zhai S, Gao H, Li Y, Zhang X, Wu G (2019) Development and strategy of reference materials for the DNA-based detection of genetically modified organisms. Anal. Bioanal. Chem. 411(9):1729-44 